\title{
Low Frequency of Adenovirus, Rotavirus, and Norovirus in Pediatric Diarrheal Samples from Central Iran
}

\author{
Elnaz Abbasi (iD) ${ }^{1}$, Mahdieh Mondanizadeh (iD) ${ }^{2}$, Alex van Belkum (iD) ${ }^{3}$ and Ehsanollah Ghaznavi-Rad \\ (iD) $1,2,{ }^{*}$ \\ ${ }^{1}$ Department of Microbiology \& Immunology, Faculty of Medicine, Arak University of Medical Sciences, Arak, Iran \\ ${ }^{2}$ Molecular and Medicine Research Center, Faculty of Medicine Arak University of Medical Sciences, Arak, Iran \\ ${ }^{3}$ BioMérieux, Data Analytics Department, La Balme les Grottes, France \\ "Corresponding author: Department of Microbiology \& Immunology, Faculty of Medicine, Arak University of Medical Sciences, Arak, Iran. Email: ghaznaviehs@yahoo.com
}

Received 2021 August 07; Revised 2021 November 06; Accepted 2021 November 14.

\begin{abstract}
Background: Acute viral gastroenteritis is a disorder that affects children globally but mostly in developing countries. Adenoviruses, rotaviruses, and noroviruses are the leading viral causes of childhood gastroenteritis.

Objectives: This study is the first to investigate the frequency of these viruses in diarrheal samples from pediatric patients living in central Iran.

Methods: A total of 173 samples of pediatric diarrhea, from May 2015 to May 2016, were included in this descriptive cross-sectional study. The samples were analyzed using in-house developed PCR and reverse transcription (RT)-PCR methods to investigate the frequency of adenoviruses, rotaviruses, and noroviruses.

Results: Out of 173 samples of pediatric diarrhea, eight were shown to contain enteric viruses (4.6\%): (1) four with adenoviruses (2.3\%); (2) three with rotaviruses (1.7\%); and (3) one with a genogroup II norovirus ( $0.6 \%)$. Most of the positive samples were obtained from children under the age of seven. The most common additional clinical symptoms in pediatric patients with viral agents were fever, vomiting, and abdominal pain.

Conclusions: In central Iran, adenoviruses and rotaviruses were rarely found as agents responsible for gastroenteritis. Although viral gastroenteritis in this area had less frequency than bacterial gastroenteritis, we need to monitor all enteropathogenic agents for longer periods to understand better real endemicity and the possibility of unexpected viral enteritis outbreaks.
\end{abstract}

Keywords: Adenovirus, Rotavirus, Norovirus, Children Diarrhea, Pediatrics, Iran

\section{Background}

Enteric viral infections are a significant worry for public health (1). In 2016, diarrhea caused more than 1.6 million deaths worldwide and was the fifth leading cause of death (446,000 deaths) among those younger than five years (2). Nevertheless, the role of acute diarrheal disease in the morbidity and mortality of pediatric patients under five years of age is still significant, particularly in low-income populations living in areas with little or no infrastructure (3). Diarrhea has a notable influence on the quality of life of pediatric patients and their families (4). Viruses account for up to $40 \%$ of all severe cases of diarrhea among children in some emerging economies (5). Adenoviruses, rotaviruses, and noroviruses are the leading causes of viral gastroenteritis, especially in young children (6-8). Rotavirus is the primary etiologic agent of acute, severe gastroenteritis in infants worldwide, causing an estimated 128,515 deaths per annum (2). Rotavirus vaccination has not yet been introduced in many developing countries, including Iran.

The detection and identification of viruses are not routinely performed in Iran's hospitals and medical diagnostic laboratories. No comprehensive studies have been conducted to determine the role of viral agents in pediatric diarrhea in the central part of the country. Detailed investigations into the causal agents of diarrhea can provide valuable understanding for planning control strategies to reduce the incidence of this significant public health concern, mitigate its financial burden, and help improve the quality of health care facilities (9).

\section{Objectives}

The purpose of this study was to evaluate the frequency of adenoviruses, rotaviruses, and noroviruses in children 
in central Iran using PCR and reverse transcription (RT)PCR methods.

\section{Methods}

\subsection{Sample Collection}

This study was confirmed by the Ethics Committee of Arak University of Medical Sciences, numbered 93-17610. This descriptive cross-sectional study collected 173 out of 658 stool samples from under 16-year-old pediatric patients with diarrhea. The patients were referred to a Pediatric's Educational-Therapeutic Diagnostic Center affiliated with the Arak University of Medical Sciences from the beginning of May 2015 to the end of May 2016. The medical center admits 1,500 children a year on average, of whom 268 are hospitalized in the infectious ward and 140 are hospitalized with infectious gastroenteritis. The pediatric diarrheal samples in this study were collected during all four seasons and were assessed immediately after receipt by the laboratory. Written informed consent was obtained, and questionnaires were filled in by the guardians or parents of participants under 16-years-old (Amir Kabir Hospital). Diarrhea was defined as at least three liquid or loose stools in a 24-h period accompanied by at least one of the following symptoms: abdominal pain, vomiting, fever, watery diarrhea, or dehydration.

Clinical signs and symptoms were recorded. All participants had diarrhea, dehydration, and fever at the time of referral, and none had any other illness. Each 5-mL fecal sample was immediately added to a phosphate-buffered saline (PBS) medium, placed on ice, and transported to the molecular laboratory in less than 40 minutes. Deoxyribonucleic acid (DNA) and ribonucleic acid (RNA) were then either immediately extracted from the samples or after the samples were placed at $-70^{\circ} \mathrm{C}$ for later extraction.

\subsection{DNA and RNA Extraction}

The RNA and DNA were extracted directly from stool samples using the QIAamp DNA Stool Mini Kit and QIAamp Viral RNA Kit (Qiagen GmbH, Hilden, Germany) following the manufacturer's protocols. The quantity and purity of the extracted RNA and DNA were measured with a NanoDrop machine (Thermo Fisher Scientific, Waltham. MA, USA).

\subsection{PCR and RT-PCR Amplification}

We used PCR and RT-PCR assays to investigate the presence of pathogenic viruses (Table 1). All the primers and assays were developed and validated at the Virology Laboratory of Arak University of Medical Sciences. The analytical sensitivity and limit of detection (LOD) of the assays had already been determined by the laboratory with dilution series of the viruses using a commercial control for adenoviruses (Argene, Verniolle, France) and in vitro transcribed RNA for rota and noroviruses. For each control, dilutions of $100,200,500,103$, and 104 copies/mL of the materials were analyzed on three different days in six replicates. The LOD for adenovirus, rotavirus, and norovirus PCR tests was 212,518 , and 388 copies/mL, respectively.

The final volume of the PCR was $25 \mu \mathrm{L}$, including $2 \mu \mathrm{L}$ of DNA template ( $5 \mathrm{ng}$ ), $8 \mu \mathrm{L}$ of double-distilled water, 0.5 $\mu \mathrm{L}$ of Taq DNA polymerase (2.5 units), $12.5 \mu \mathrm{L}$ of master mix (1X), and $1 \mu \mathrm{L}$ each of the forward and reverse primers (10 pM) (all bought from Yekta Tajhiz Company, Iran). The final volume of the RT-PCR was $20 \mu \mathrm{L}$ and included $10 \mu \mathrm{L}$ of master mix (1X), $5 \mu \mathrm{L}$ of RNA template ( $5 \mathrm{ng}$ ), $0.5 \mu \mathrm{L}$ each of the forward and reverse primers (10 pM), $0.4 \mu \mathrm{L}$ of RTEnzyme, and 3.6 $\mu \mathrm{L}$ of RNase-free water(all purchased from Yekta Tajhiz Company, Iran). A single positive sample for each pathogen was used for sequencing (Gene Fanavaran Company, Tehran, Iran), and the resulting sequences were confirmed using Basic Local Alignment Search Tool (BLAST) analysis. Positive controls of adenovirus, rotavirus, and genogroup I, II norovirus were obtained from the Virology Laboratory of Arak University of Medical Sciences.

\section{Results}

Of the 173 samples of pediatric diarrhea, eight (4.6\%) were positive for diarrheal viruses, including four $(2.3 \%)$ with adenoviruses, three $(1.7 \%)$ with rotaviruses, and one (0.6\%) with a genogroup II norovirus. Four (50\%) male and four $(50 \%)$ female patients were diagnosed with the viral infection. Of the participants, 129 (74.5\%) were hospitalized, and 44 (25.4\%) were outpatients. The hospitalization period ranged from three to five days (Table 2 ).

\subsection{Adenovirus}

One (25\%) male and three (75\%) female patients were diagnosed with the adenoviral infection. The average age of the infectious patients was four years and eight months. The youngest patient was a 12-month-old girl, and the oldest was a seven-year-old boy. The clinical symptoms of pediatric patients with adenovirus infection included abdominal pain, vomiting, fever, watery diarrhea, dehydration (100\%), and bloody stool (75\%).

\subsection{Rotavirus}

Of three (1.7\%) patients infected with rotavirus, all (100\%) were male, giving a male-to-female infection ratio of $1: 0$. The average age of these patients was three 


\begin{tabular}{|c|c|c|c|c|}
\hline Pathogen & Primer & Size & Sequence $5^{\prime} \rightarrow 3^{\prime}$ & References \\
\hline \multirow{2}{*}{ Adenovirus } & \multirow{2}{*}{ hexon } & \multirow{2}{*}{$169 \mathrm{bp}$} & F: 5-CCCMTTYAACCACCACCG -3 & \multirow{2}{*}{ (8) } \\
\hline & & & R:5-ACATCCTTBCKGAAGTTCCA-3 & \\
\hline \multirow{2}{*}{ Rotavirus } & \multirow{2}{*}{ GCMP } & \multirow{2}{*}{205 bp } & F: 5-CAAATGATTCAGAATCTATTG -3 & \multirow{2}{*}{ (6) } \\
\hline & & & R: 5-GTTTCTGTACTAGCTGGTGAA-3 & \\
\hline \multirow{2}{*}{$\begin{array}{l}\text { Genogroup I } \\
\text { Norovirus }\end{array}$} & Mon431 & \multirow{2}{*}{213 bp } & F: 5-TGGACICGYGGICCYAAYCA-3 & \multirow{2}{*}{ (7) } \\
\hline & Mon434 & & R:5- GAASCGCATCCARCGGAACAT -3 & \\
\hline \multirow{2}{*}{$\begin{array}{l}\text { Genogroup II } \\
\text { Norovirus }\end{array}$} & Mon431 & \multirow{2}{*}{$213 \mathrm{bp}$} & F: 5-TGGACIAGRGGICCYAAYCA-3 & \multirow{2}{*}{ (7) } \\
\hline & Mon433 & & R:5-GAAYCTCATCCAYCTGAACAT-3 & \\
\hline
\end{tabular}

\begin{tabular}{|c|c|c|c|c|c|c|c|c|c|c|c|c|c|c|}
\hline \multirow{2}{*}{\multicolumn{2}{|c|}{$\begin{array}{l}\text { Age Groups and } \\
\text { Gender }\end{array}$}} & \multirow{2}{*}{$\begin{array}{l}\text { Viral Di- } \\
\text { arrheal } \\
\text { Infection }\end{array}$} & \multicolumn{4}{|c|}{ Hospitalized Patients and Outpatients $(\mathrm{H} / \mathrm{O})$} & \multicolumn{2}{|c|}{ Combining Population } & \multirow{2}{*}{$\begin{array}{c}\text { Watery } \\
\text { Diarrhea }\end{array}$} & \multirow[b]{2}{*}{ Dehydration } & \multirow{2}{*}{$\begin{array}{l}\text { Abdominal } \\
\text { Pain }\end{array}$} & \multirow[b]{2}{*}{ Fever } & \multirow{2}{*}{$\begin{array}{c}\text { Bloody } \\
\text { Stool }\end{array}$} & \multirow[b]{2}{*}{ Vomiting } \\
\hline & & & Adenovirus & Rotavirus & \multicolumn{2}{|c|}{$\begin{array}{l}\text { Norovirus } \\
\end{array}$} & Rural & Urban & & & & & & \\
\hline \multicolumn{15}{|l|}{$\leq 1 \cdot \leq 2$} \\
\hline & Male & 1 & 0 & $1(0)$ & 0 & 0 & 0 & 1 & 1 & 1 & 1 & 1 & 0 & 0 \\
\hline & Female & 2 & $1(0)$ & 0 & 0 & $1(\mathrm{H})$ & 0 & 2 & 2 & 2 & 2 & 2 & 1 & 1 \\
\hline & Total (\%) & $3 / 8(37.5)$ & $\begin{array}{l}1 / 4(25) \\
(0)\end{array}$ & $\begin{array}{c}1 / 3(33.3) \\
(0)\end{array}$ & 0 & $\begin{array}{c}1 / 1(100) \\
(\mathrm{H})\end{array}$ & 0 & $3 / 5(60)$ & $3 / 8(37.5)$ & $3 / 8(37.5)$ & $3 / 8(37.5)$ & $3 / 8(37.5)$ & $1 / 8(12.5)$ & $1 / 8(12.5)$ \\
\hline \multicolumn{15}{|l|}{$<2 \cdot \leq 3$} \\
\hline & Male & 1 & 0 & $1(\mathrm{H})$ & 0 & 0 & 0 & 1 & 1 & 1 & 1 & 1 & 0 & 1 \\
\hline & Female & 0 & 0 & 0 & 0 & 0 & 0 & 0 & 0 & 0 & 0 & 0 & 0 & 0 \\
\hline & Total (\%) & $1 / 8(12.5)$ & 0 & $\begin{array}{c}1 / 3(33.3) \\
(H)\end{array}$ & 0 & 0 & 0 & $1 / 5(20)$ & $1 / 8(12.5)$ & $1 / 8(12.5)$ & $1 / 8(12.5)$ & $1 / 8(12.5)$ & $0 / 8(0)$ & $1 / 8(12.5)$ \\
\hline \multicolumn{15}{|l|}{$<3 \cdot \leq 4$} \\
\hline & Male & 0 & 0 & 0 & 0 & 0 & 0 & 0 & 0 & 0 & 0 & 0 & 0 & 0 \\
\hline & Female & 0 & 0 & 0 & 0 & 0 & 0 & 0 & 0 & 0 & 0 & 0 & 0 & 0 \\
\hline & Total (\%) & $0 / 8(0)$ & 0 & 0 & 0 & 0 & 0 & 0 & $0 / 8(0)$ & $0 / 8(0)$ & $0 / 8(0)$ & $0 / 8(0)$ & $0 / 8(0)$ & $0 / 8(0)$ \\
\hline \multicolumn{15}{|l|}{$<4 \cdot \leq 5$} \\
\hline & Male & 0 & 0 & 0 & 0 & 0 & 0 & 0 & 0 & 0 & 0 & 0 & 0 & 0 \\
\hline & Female & 0 & o & 0 & 0 & 0 & 0 & 0 & 0 & 0 & 0 & 0 & 0 & 0 \\
\hline & Total (\%) & $0 / 8(0)$ & 0 & 0 & 0 & 0 & 0 & 0 & $0 / 8(0)$ & $0 / 8(0)$ & $0 / 8(0)$ & $0 / 8(0)$ & $0 / 8(0)$ & $0 / 8(0)$ \\
\hline \multicolumn{15}{|l|}{$<5 \cdot \leq 6$} \\
\hline & Male & 0 & 0 & 0 & 0 & 0 & 0 & 0 & 0 & 0 & 0 & 0 & 0 & 0 \\
\hline & Female & 2 & $\begin{array}{l}2(1 \mathrm{H} \text { and } \\
1 \mathrm{O})\end{array}$ & 0 & 0 & 0 & 1 & 1 & 2 & 2 & 2 & 2 & 1 & 2 \\
\hline & Total (\%) & $2 / 8(25)$ & $\begin{array}{c}2 / 4(50) \\
(1 \mathrm{H} \text { and } \\
10)\end{array}$ & 0 & 0 & 0 & $1 / 3(33.3)$ & $1 / 5(20)$ & $2 / 8(25)$ & $2 / 8(25)$ & $2 / 8(25)$ & $2 / 8(25)$ & $1 / 8(12.5)$ & $2 / 8(25)$ \\
\hline \multicolumn{15}{|l|}{$<6 \cdot \leq 7$} \\
\hline & Total (\%) & $2 / 8(25)$ & $\begin{array}{l}1 / 4(25) \\
(H)\end{array}$ & $\begin{array}{c}1 / 3(33.3) \\
(\mathrm{H})\end{array}$ & 0 & 0 & $2 / 3(66.6)$ & 0 & $2 / 8(25)$ & $2 / 8(25)$ & $2 / 8(25)$ & $2 / 8(25)$ & $1 / 8(12.5)$ & $1 / 8(12.5)$ \\
\hline Final total & & $8 / 173(4.6)$ & $\begin{array}{c}4 / 8(50) \\
(2 \mathrm{O} \text { and } \\
2 \mathrm{H})\end{array}$ & $\begin{array}{c}3 / 8(37.5) \\
(10 \text { and } \\
2 \mathrm{H})\end{array}$ & 0 & $\begin{array}{c}1 / 8(12.5) \\
(1 \mathrm{H})\end{array}$ & $3 / 8(37.5)$ & $5 / 8(62.5)$ & $8 / 8(100)$ & $8 / 8(100)$ & $8 / 8(100)$ & $8 / 8(100)$ & $3 / 8(37.5)$ & $5 / 8(62.5)$ \\
\hline
\end{tabular}

years and six months. The clinical symptoms of the pediatric patients with rotavirus infection included abdominal pain, fever, watery diarrhea, dehydration (100\%), vomiting (33.3\%), and bloody stool (0\%).

\subsection{Norovirus}

A one-year-old girl was infected with a genogroup II norovirus. The clinical symptoms of the pediatric patients with norovirus infection included abdominal pain, vomiting, fever, watery diarrhea, and dehydration (100\%). Coin- 
fection with adenoviruses and rotaviruses was observed in a seven-year-old boy (0.5\%). Gastroenteritis severity was measured using the Vesikari Scoring System (Table 3).

\section{Discussion}

The pathophysiological role of most enteric viruses in gastroenteric disease remains uncertain, underlining the requirement for studying the epidemiology of these viruses (1). Viral gastroenteritis mainly occurs in the winter worldwide, with transmission chiefly through the fecal-oral route (10). This is the first report to estimate the frequency of adenoviral, noroviral, and rotaviral diseases in central Iran, which suggested that the frequency of these three most important species in the samples of pediatric patients was lower than that of bacterial agents (11-13). All samples were simultaneously tested for viruses, bacteria, and parasites, and the frequencies of DEC (35.1\%), Campylobacter jejuni (19.5\%), Shigella (8.2\%), and Salmonella (9.1\%) were higher than those of viral and parasitic agents and other bacterial agents (11-17). The samples were taken during DEC and campylobacteriosis outbreaks, which may explain the observed lower frequencies of viral enteropathogens (11-13).

In similar studies in Iran, adenoviral frequency in pediatric diarrheal stool samples was reported to be $2.3 \%$ in northern Iran and 9\% in Shiraz $(18,19)$. Adenoviral frequency was $1.5 \%$ in Thailand and about $14 \%$ in Turkey (20, 21). The PCR test for diagnosing adenoviral infections is considered the gold standard (22). There are great hardships in organizing the diagnosis of adenoviral diarrheal infections, causing the prevalence of these viral infections to be underestimated (22).

In this study, the frequency of rotavirus in pediatric diarrheal patients was $1.7 \%$ (three cases). In similar studies in Iran, the rotaviral frequency in pediatric diarrheal stool samples was reported to be $35 \%$ in Ahvaz and $42 \%$ in Shi$\operatorname{raz}(19,23)$. In other countries, the rotaviral frequency was $6.1 \%$ in Japan and $21 \%$ in France $(20,24)$. The differences between the results may be due to the duration of the studies, age of patients, different seasons of study, and the methods used for detecting rotavirus (25). This study was conducted during the hot and cold seasons of the year. The outbreaks of rotaviral gastroenteritis vary with season (19). Seventyeight percent of rotaviral gastroenteritis occurred during winter, while only $2 \%$ of this infection was seen among diarrheal patients in summer. This pattern is generally seen in temperate climate areas, but it does not apply to all climate conditions. Another study mentioned that the seasonal pattern of rotaviral gastroenteritis was not global, and in countries within $10^{\circ}$ of the equator, infections happened year-round (18).
In similar studies, the peaks of rotaviral infections in Iran (Tehran) and Latin America were in the autumn and winter $(26,27)$. Rotavirus outbreaks have been previously reported from different geographical locations in Europe and the USA (28). In Europe, rotavirus is widespread during January-March (29). Nevertheless, in tropical countries like Malaysia, a seasonal pattern of rotavirus frequency was not found (29). The annual seasonality of viral enteritis depends on climate globally. In colder climates, a higher frequency of rotavirus was found, and relatively low humidity and dry climates were detected in some reports (10). The higher prevalence in the present study may be due to the time family members stayed indoors in cold weather, leading to enhanced close contact transmission, as dry conditions encourage the aerosol formation of virus-laden particles from patients' feces (10). Improvements in sanitation and the availability of clean water have not reduced the number of rotavirus diarrheal cases (30). Although the frequency of rotavirus in this study was low, more studies are needed to confirm the results before deciding on the need for vaccination in the central region of Iran.

In this study, the frequency of norovirus was $0.5 \%$ (one case). In similar studies in Iran, the noroviral frequency in pediatric diarrheal stool samples was reported to be $0.6 \%$ in Tabriz and $8.8 \%$ in Tehran $(26,31)$. The noroviral frequency was $5.8 \%$ in China and $14.8 \%$ in Japan $(32,33)$. The worldwide reported prevalence of norovirus in the fecal samples of pediatric patients with sporadic acute gastroenteritis has a broad range, depending on whether patients have been hospitalized or not, the age of children, and the study methodology (10).

This study observed coinfection with adenoviruses and rotaviruses in a seven-year-old boy (0.5\%). In similar studies, adenovirus-rotavirus coinfection frequency in pediatric diarrheal stool samples was $1.3 \%$ in Italy and $8 \%$ in Turkey (21, 34). Adenovirus and rotavirus coinfections have been found between 1.2 and $8.2 \%$ in some other reports (10). An eight-percent coinfection with different rotaviruses and noroviruses was reported in China in 2011 (35).

Clinically, it would be challenging to separate viral gastroenteritis from gastroenteritis caused by other microorganisms, particularly bacterial gastroenteritis. Molecular techniques increased the overall diagnostic efficacy by $10 \%$ and by $2.5 \%$ for each adenovirus and rotavirus (10). Studies detecting adenoviruses using PCR have commonly reported higher frequencies (36).

The weaknesses of this study include the small number of samples (due to financial constraints) from a limited area. Samples from all over the country will provide more robust results. This study's strengths include standardized sampling, transportation, and storage methods. The 


\begin{tabular}{lcccc}
\hline Table 3. Diarrheal Severity Distribution & & & & \\
\hline Severity & Total & Adenovirus & Rotavirus & Norovirus \\
\hline Mild $(\%)($ score $<$ 7) & 0 & 0 & 0 & 0 \\
Moderate $(\%)($ score 7 - 10) & $3 / 8(37.5)$ & $2 / 4(50)$ & $1 / 3(33.3)$ & 0 \\
Severe $(\%)($ score $\geq \mathbf{1 1})$ & $5 / 8(62.5)$ & $2 / 4(50)$ & $2 / 3(66.6)$ & $1 / 1(100)$ \\
\hline
\end{tabular}

DNA/RNA extraction and PCR/RT-PCR test were also carefully performed.

\subsection{Conclusion}

Adenovirus, norovirus, and rotavirus were rarely found as viral agents responsible for gastroenteritis among children in central Iran. Although the viral gastroenteritis frequency has been lower in this area than bacterial gastroenteritis frequency (11-13), the long-term monitoring of all enteropathogenic agents should continue to screen for the unexpected occurrence of outbreaks and get better visibility on the precise seasonality of viral and bacterial diarrhea. Doing so will help better understand the precise epidemiology of this severe disease and improve appropriate medical diagnosis and management of diarrhea in pediatric patients.

\section{Acknowledgments}

The authors gratefully acknowledge the educational assistance of Arak University of Medical Sciences due to its financial contributions to and support of this study. This paper has been submitted and published as a preprinted form in Research Square since 31 Mar 2020.

\section{Footnotes}

Authors' Contribution: EGR conceptualized and designed the study. EA was involved in data collection, generation, and data analysis. MM supervised the lab work and wrote the first draft. AvB performed data analysis and paper writing. All authors have read and approved this version of the manuscript.

Conflict of Interests: AvB is an employee of bioMerieux, a company designing, developing, and selling infectious disease tests. The company did not influence the design and conduct of the study and manuscript writing. The authors report no other conflicts of interest in this work.

Data Reproducibility: The data presented in this study are openly available in one of the repositories or will be available on request from the corresponding author by this journal representative at any time during submission or after publication. Otherwise, all consequences of possible withdrawal or future retraction will be with the corresponding author. All data pertaining to this study are in the sample collection and results sections in the manuscript. The datasets analyzed and/or used in the current study are available from the corresponding author on reasonable request.

Ethical Approval: This study was confirmed by the Ethics Committee of Arak University of Medical Sciences under No. 93-176-10.

Funding/Support: This work was financially supported by the Arak University of Medical Sciences (Number: 93-17610). The funder had no role in the design of the study and collection, analysis, and interpretation of data and writing the manuscript. This funding was only for purchasing materials in this study. No additional external funding was received for this study.

Informed Consent: Written informed consent was obtained, and questionnaires were filled in by the guardians or parents of participants under 16-years-old (Amir Kabir hospital).

\section{References}

1. Biscaro V, Piccinelli G, Gargiulo F, Ianiro G, Caruso A, Caccuri F, et al. Detection and molecular characterization of enteric viruses in children with acute gastroenteritis in Northern Italy. Infect Genet Evol. 2018;60:35-41. doi: 10.1016/j.meegid.2018.02.011. [PubMed: 29438743].

2. GBD Diarrhoeal Disease Collaborators. Estimates of the global, regional, and national morbidity, mortality, and aetiologies of diarrhoea in 195 countries: A systematic analysis for the Global Burden of Disease Study 2016. Lancet Infect Dis. 2018;18(11):1211-28. doi: 10.1016/S1473-3099(18)30362-1. [PubMed: 30243583]. [PubMed Central: PMC6202444].

3. Reis TA, Assis AS, do Valle DA, Barletta VH, de Carvalho IP, Rose TL, et al. The role of human adenoviruses type 41 in acute diarrheal disease in Minas Gerais after rotavirus vaccination. Braz J Microbiol. 2016;47(1):243-50. doi: 10.1016/j.bjm.2015.11.011. [PubMed: 26887251]. [PubMed Central: PMC4822746].

4. Dona D, Mozzo E, Scamarcia A, Picelli G, Villa M, Cantarutti L, et al. Community-Acquired Rotavirus Gastroenteritis Compared with Adenovirus and Norovirus Gastroenteritis in Italian Children: A Pedianet Study. Int J Pediatr. 2016;2016:5236243. doi: 10.1155/2016/5236243. [PubMed: 26884770]. [PubMed Central: PMC4738938].

5. Kotloff KL. The Burden and Etiology of Diarrheal Illness in Developing Countries. Pediatr Clin North Am. 2017;64(4):799-814. doi: 10.1016/j.pcl.2017.03.006. [PubMed: 28734511].

6. Khamrin P, Okame M, Thongprachum A, Nantachit N, Nishimura S, Okitsu S, et al. A single-tube multiplex PCR for rapid detection in feces 
of 10 viruses causing diarrhea. J Virol Methods. 2011;173(2):390-3. doi: 10.1016/j.jviromet.2011.02.012. [PubMed: 21349292].

7. Chatterjee NK, Moore DW, Monroe SS, Glass RI, Cambridge MJ, Kondracki SF, et al. Molecular epidemiology of outbreaks of viral gastroenteritis in New York State, 1998-1999. Clin Infect Dis. 2004;38(Suppl 3):S303-10. doi: 10.1086/381600. [PubMed: 15095203].

8. Hsu CC, Tokarz R, Briese T, Tsai HC, Quan PL, Lipkin WI. Use of staged molecular analysis to determine causes of unexplained central nervous system infections. Emerg Infect Dis. 2013;19(9):1470-7. doi: 10.3201/eid1909.130474. [PubMed: 23965845]. [PubMed Central: PMC3810931].

9. Nelson EA, Bresee JS, Parashar UD, Widdowson MA, Glass RI; Asian Rotavirus Surveillance Network. Rotavirus epidemiology: The Asian Rotavirus Surveillance Network. Vaccine. 2008;26(26):3192-6. doi: 10.1016/j.vaccine.2008.03.073. [PubMed: 18485546].

10. Bicer S, Col D, Erdag GC, Giray T, Gurol Y, Yilmaz G, et al. A retrospective analysis of acute gastroenteritis agents in children admitted to a university hospital pediatric emergency unit. Jundishapur J Microbiol. 2014;7(4). e9148. doi: 10.5812/jjm.9148. [PubMed: 25147694]. [PubMed Central: PMC4138623].

11. Abbasi E, Mondanizadeh M, van Belkum A, Ghaznavi-Rad E. MultiDrug-Resistant Diarrheagenic Escherichia coli Pathotypes in Pediatric Patients with Gastroenteritis from Central Iran. Infect Drug Resist. 2020;13:1387-96. doi: 10.2147/IDR.S247732. [PubMed: 32523359]. [PubMed Central: PMC7234969].

12. Abbasi E, van Belkum A, Ghaznavi-Rad E. Quinolone and MacrolideResistant Campylobacter jejuni in Pediatric Gastroenteritis Patients from Central Iran. Microb Drug Resist. 2019;25(7):1080-6. doi: 10.1089/mdr.2018.0455. [PubMed: 31021299].

13. Abbasi E, Abtahi H, van Belkum A, Ghaznavi-Rad E. Multidrugresistant Shigella infection in pediatric patients with diarrhea from central Iran. Infect Drug Resist. 2019;12:1535-44. doi: 10.2147/IDR.S203654. [PubMed: 31239729]. [PubMed Central: PMC6559769].

14. Abbasi E, Amouzandeh-Nobaveh A, Ghaznavi-Rad E. Frequency of Listeria monocytogenes Isolated from Diarrhea Samples of Pediatric Patients at Central Iran. Rep Biochem Mol Biol. 2019;8(2):172-7. [PubMed: 31832442]. [PubMed Central: PMC6844618].

15. Abbasi E, Khansari-Nejad B, Abtahi H, Akbari M, Ghaznavi-Rad E. Low Prevalence of Aeromonas hydrophilain Infectious Diarrhea Samples of Pediatric Patients in Arak, Iran. Rep Biochem Mol Biol. 2016;5(1):15-9. [PubMed: 28070529]. [PubMed Central: PMC5214678].

16. Abbasi E, Amouzandeh-Nobaveh A, Ghaznavi-Rad E. The Frequency of the Intestinal Parasites Giardia Lamblia and Entamoeba Histolytica in Pediatric Diarrhea Specimens from Central Iran. Open Microbiol J. 2020;14(1):53-6. doi: 10.2174/1874285802014010053.

17. Abbasi E, Ghaznavi-Rad E. Quinolone resistant Salmonella species isolated from pediatric patients with diarrhea in central Iran. BMC Gastroenterol. 2021;21(1):140. doi: 10.1186/s12876-021-01719-3. [PubMed: 33784974]. [PubMed Central: PMC8010990].

18. Hamkar R, Yahyapour Y, Noroozi M, Nourijelyani K, Jalilvand S, Adibi $\mathrm{L}$, et al. Prevalence of Rotavirus, Adenovirus, and Astrovirus Infections among Patients with Acute Gastroenteritis in, Northern Iran. Iran J Public Health. 2010;39(2):45-51. [PubMed: 23113006]. [PubMed Central: PMC3481758].

19. Motamedifar M, Amini E, Talezadeh Shirazi P. Frequency of rotavirus and adenovirus gastroenteritis among children in shiraz, iran. Iran Red Crescent Med J. 2013;15(8):729-33. doi: 10.5812/ircmj.4415. [PubMed: 24578843]. [PubMed Central: PMC3918200].

20. Kittigul L, Pombubpa K, Taweekate Y, Yeephoo T, Khamrin P, Ushijima H. Molecular characterization of rotaviruses, noroviruses, sapovirus, and adenoviruses in patients with acute gastroenteritis in Thailand. J Med Virol. 2009;81(2):345-53. doi: 10.1002/jmv.21380. [PubMed: 19107961].

21. Topkaya AE, Aksungar B, Özakkafl F, Çapan N. Examination of ro- tavirus and enteric adenovirus in children with acute gastroenteritis. Türk Mikrobiyol Cem Derg. 2006;36(4):210-3.

22. Sanaei Dashti A, Ghahremani P, Hashempoor T, Karimi A. Molecular Epidemiology of Enteric Adenovirus Gastroenteritis in under-FiveYear-Old Children in Iran. Gastroenterol Res Pract. 2016;2016:2045697. doi: 10.1155/2016/2045697. [PubMed: 26880883]. [PubMed Central: PMC4736959].

23. Ziaei Kajbaf T, Shamsizadeh A, Kalvandi G, Macvandi M. Relative Frequency of Rotavirus and Adenovirus Among Children Aged 1-60 Months Hospitalized With Acute Diarrhoea in South-Western, Iran. Jundishapur J Microbiol. 2012;6(1):47-50. doi: 10.5812/jjm.4072.

24. Tran A, Talmud D, Lejeune B, Jovenin N, Renois F, Payan C, et al. Prevalence of rotavirus, adenovirus, norovirus, and astrovirus infections and coinfections among hospitalized children in northern France.J Clin Microbiol. 2010;48(5):1943-6. doi: 10.1128/JCM.02181-09. [PubMed: 20305010]. [PubMed Central: PMC2863921].

25. Al-Badani A, Al-Areqi L, Majily A, Al-Sallami S, Al-Madhagi A, Amood Al-Kamarany M. Rotavirus Diarrhea among Children in Taiz, Yemen: Prevalence-Risk Factors and Detection of Genotypes. Int J Pediatr. 2014;2014:928529. doi: 10.1155/2014/928529. [PubMed: 25197286]. [PubMed Central: PMC4145802].

26. Mousavi Nasab SD, Sabahi F, Makvandi M, Mirab Samiee S, Nadji SA, Ravanshad M. Epidemiology of Rotavirus-Norovirus Co-Infection and Determination of Norovirus Genogrouping among Children with Acute Gastroenteritis in Tehran, Iran. Iran Biomed J. 2016;20(5):2806. doi: 10.22045/ibj.2016.05. [PubMed: 27137790]. [PubMed Central: PMC5075141].

27. Castello AA, Arvay ML, Glass RI, Gentsch J. Rotavirus strain surveillance in Latin America: A review of the last nine years. Pediatr Infect Dis J. 2004;23(Suppl 10):S168-72. doi: 10.1097/01.inf.0000142466.57262.2a. [PubMed: 15502697].

28. Bernstein DI. Rotavirus overview. Pediatr Infect Dis J. 2009;28(3 Suppl):S50-3. doi: 10.1097/INF.0b013e3181967bee. [PubMed: 19252423].

29. Akan H, Izbirak G, Gurol Y, Sarikaya S, Gunduz TS, Yilmaz G, et al. Rotavirus and adenovirus frequency among patients with acute gastroenteritis and their relationship to clinical parameters: a retrospective study in Turkey. Asia Pac Fam Med. 2009;8(1):8. doi: 10.1186/1447056X-8-8. [PubMed: 19943964]. [PubMed Central: PMC2794259].

30. Aminu M, Ahmad AA, Umoh JU, Dewar J, Esona MD, Steele AD. Epidemiology of rotavirus infection in north-western Nigeria. $J$ Trop Pediatr. 2008;54(5):340-2. doi: 10.1093/tropej/fmn021. [PubMed: 18344546].

31. Adabian S, Fallah F, Gachkar L, Jadali F, Tabatabaei S, Esmaeilnejad N. Detection of norovirus in stool samples by RT-PCR in 5 disease centers in Iran. BMC Infect Dis. 2012;12(S1). doi: 10.1186/1471-2334-12-s1-010.

32. Ouyang $\mathrm{Y}$, Ma H, Jin M, Wang X, Wang J, Xu L, et al. Etiology and epidemiology of viral diarrhea in children under the age of five hospitalized in Tianjin, China. Arch Virol. 2012;157(5):881-7. doi: 10.1007/s00705-012-1235-9. [PubMed: 22318672].

33. Akihara S, Phan TG, Nguyen TA, Hansman G, Okitsu S, Ushijima H. Existence of multiple outbreaks of viral gastroenteritis among infants in a day care center in Japan. Arch Virol. 2005;150(10):2061-75. doi: 10.1007/s00705-005-0540-y. [PubMed: 15841336].

34. Lin HC, Kao CL, Lu CY, Lee CN, Chiu TF, Lee PI, et al. Enteric adenovirus infection in children in Taipei. J Microbiol Immunol Infect. 2000;33(3):176-80. [PubMed: 11045381].

35. Zhang S, Chen TH, Wang J, Dong C, Pan J, Moe C, et al. Symptomatic and asymptomatic infections of rotavirus, norovirus, and adenovirus among hospitalized children in Xi'an, China. J Med Virol. 2011;83(8):1476-84. doi: 10.1002/jmv.22108. [PubMed: 21618552].

36. Moyo SJ, Hanevik K, Blomberg B, Kommedal O, Nordbo SA, Maselle $S$, et al. Prevalence and molecular characterisation of human adenovirus in diarrhoeic children in Tanzania; a case control study. BMC Infect Dis. 2014;14:666. doi: 10.1186/s12879-014-0666-1. [PubMed: 25495029]. [PubMed Central: PMC4266963]. 